\title{
Fazendas Paulistas de Café: uma possibilidade de inventário do patrimônio rural em ambiente virtual
}

São Paulo coffee plantations: possibility of rural heritage inventory using virtual environment

\author{
> Sandra Schmitt Soster \\ Instituto de Arquitetura e Urbanismo-USP, Brasil \\ soster@sc.usp.br \\ > Luzia Sigoli Fernandes Costa \\ Universidade Federal de São Carlos-UFSCar, Brasil \\ luziasigoli@gmail.com
}

> Maria Ângela P. C. S. Bortolucci

Instituto de Arquitetura e Urbanismo-USP, Brasil mariacsb@sc.usp.br

\begin{abstract}
O Projeto "Critérios e Metodologias para realização de inventário do Patrimônio Cultural Rural Paulista" teve como objetivos o aprimoramento de um padrão de descrição da informação (PDI) para inventário e descrição de todo tipo de bem patrimonial; o inventário do patrimônio de quatro fazendas históricas; e a inserção destas informaçóes para teste em uma base de dados online. Como uma libertação das amarras físicas da visitaçáo presencial, este processo protege o patrimônio do esquecimento e da extinção através de seu registro e amplia seus horizontes ao possibilitar sua análise pela população global através de sua divulgação online.
\end{abstract}

Keywords: Fazendas históricas de café; Preservação; Patrimônio cultural paulista; Memória Virtual.

\section{Introdução}

Diversas pesquisas realizadas ao longo dos últimos anos enfatizam a necessidade de levantar e preservar o patrimônio rural antes que ele seja completamente perdido. Este projeto teve como foco de estudo quatro das fazendas históricas paulistas do ciclo do café, que cumpriram um papel importante no século XIX e nas primeiras décadas do século XX para o desenvolvimento econômico estadual e nacional, e que, atualmente, são ameaçadas de esquecimento e de destruição em decorrência de novas vertentes de desenvolvimento econômico. Neste contexto, percebe-se a necessidade e a urgência de serem implementadas metodologias e ferramentas que auxiliem o levantamento, o registro, a gestão, a preservação e a divulgação deste patrimônio ainda pouco conhecido, subestimado e maltratado pela sociedade.

Detentoras de um vasto e diversificado acervo material e imaterial, cuja riqueza e importância são inquestionáveis, na atualidade é necessário perceber as fazendas históricas paulistas como locais que guardam uma parcela peculiar da memória local e nacional e entendê-las como instituições museológicas por seu conteúdo e sua função social de manutenção deste patrimônio inestimável. Com o propósito de auxiliar as atividades museológicas de pesquisa, preservação e divulgação que devem ser desenvolvidas nestes locais, geralmente localizados fora do perímetro urbano, entendemos que é fundamental disponibilizar aos proprietários recursos para garantir sua autonomia, de modo que se libertem da necessidade de contratação de profissionais ou instituiçóes específicas para o registro, a organização e a divulgação de seus acervos.
Neste contexto, o presente artigo apresenta o projeto "Critérios e Metodologias para realização de inventário do Patrimônio Cultural Rural Paulista” e a discussão sobre a importância de prover metodologias e meios aos proprietários e cuidadores das fazendas históricas paulistas para o inventário de seus acervos a fim de proteger do esquecimento e da ruína um cenário patrimonial cujo acesso ainda é pouco estimulado. De modo que se entende que as Tecnologias de Informação e Comunicação (TICs) são instrumentos fundamentais para a preservação e a divulgaçáo do patrimônio de uma nação, ampliando a abrangência destas atividades e atuando como suportes da memória que independem de fatores espaçotemporais para transmitir sua mensagem.

\section{0 projeto de pesquisa}

O projeto de pesquisa "Critérios e Metodologias para realização de inventário do Patrimônio Cultural Rural Paulista” é coordenado pela cientista da informação Profa. Dra. Luzia Sigoli Fernandes Costa da Universidade Federal de São Carlos-UFSCar e realizado pelo grupo de pesquisa "Patrimônio cultural: memória, preservação e gestão sustentável”. Foi aprovado no Programa de Auxílio à Pesquisa - Regular, dentro da Chamada 09/2011 de Propostas FAPESP-SEC/Condephaat: inventários de identificação, análise e seleção do Patrimônio Cultural Paulista, desmembrado em dois processos 2011/501015-2 e 2012/50044-1. Está em desenvolvimento no período de 2012 a 2014 e reúne pesquisadores de diferentes instituiçóes e áreas de conhecimento para a produção de estudos multidisciplinares sobre o patrimônio cultural rural, 
buscando o desenvolvimento de tecnologias e linguagens para registro, organização, preservaçáo e visualização desse patrimônio. Este projeto é fruto de uma longa trajetória de pesquisas nesta área, desenvolvidas desde o ano de 2003, quando foi realizado ocurso de extensão "Pinhal Digital", que pretendeu "[...] entender as diversas etapas do processo produtivo cafeeiro, levantando dados tanto do patrimônio construído [...], como de fontes primárias e secundárias [...]" (Pratschke, Bortolucci \& Costa, 2006, p. 69).

Durante as atividades realizadas em campo neste primeiro curso de extensão em 2003, se percebeu a necessidade de organizar o registro dos diversos bens patrimoniais destas fazendas, desde os menores localizados no interior das edificações até as próprias construçôes e os elementos da paisagem circundantes, de modo a satisfazer as necessidades de dois tipos de públicos. De um lado, aos fazendeiros seria possibilitado o inventário de seus bens para controle interno e com a possibilidade de encaminhamento junto aos órgãos de proteção, além da gestão dos mesmos em termos de acessibilidade. Por outro lado, aos órgãos públicos e à população seriam disponibilizadas informaçóes sobre estes bens patrimoniais, auxiliando nas atividades de educação patrimonial e na consequente valorizaçáo deste patrimônio.

No ano seguinte, foi iniciado o projeto "Memória Virtual de São Carlos", Processo FAPESP 03/06434-0, com vigência de 2004 a 2008. Coordenado pelo Prof. Dr. José Carlos Maldonado da Universidade de São Paulo - São Carlos, este projeto teve o objetivo de desenvolver um sistema web para gestão integrada dos acervos históricos de valor inestimável da cidade de São Carlos, permitindo organização, armazenamento e disponibilização das informaçóes sobre este patrimônio (Maldonado, 2004). Para garantir a qualidade e a acessibilidade das informaçóes disponibilizadas neste sistema, também foi necessário o estudo das normas e dos padrôes da representação descritiva e temática. Dessa forma, foram formadas duas linhas de frente: de um lado, o desenvolvimento do sistema web pelos participantes da área de computação; e de outro lado, o estudo dos padróes por pesquisadores e alunos da Ciência da Informação.

Em seguida, foi realizado o projeto de Pesquisas em Políticas "Patrimônio cultural rural paulista: espação privilegiado para a pesquisa, ensino e turismo", Processo FAPESP 07/55999-1, com vigência de 2008 a 2012. Coordenado pelo Prof. Dr. Marcos Tognon da Universidade de Campinas, este projeto teve o objetivo de "disponibilizar instrumentos e metodologias de gestão, de conservação e de difusão para os responsáveis por esse patrimônio cultural rural, tanto os proprietários quanto as respectivas instâncias públicas pertinentes da área da cultura, da educação e do turismo" (Tognon, 2008). Pautou sua atuação sobre um amplo diagnóstico do Patrimônio Cultural Rural Paulista, representado por dezesseis fazendas históricas localizadas em cinco regióes do Estado de São Paulo: Vale do Paraíba, Itu, Limeira, Mococa e Sáo Carlos.

Neste sentido, o projeto atual retoma e aprofunda as discussóes dos projetos anteriores e está pautado em duas frentes de pesquisa, descritas a seguir.

\section{Padrão de Descrição da Informação}

A primeira trabalhou com o aprimoramento do chamado Padrão de Descrição da Informação (PDI), uma metodologia de descrição dos bens patrimoniais ${ }^{1}$ composta por um conjunto de campos descritivos a serem preenchidos pelo catalogador, com o intuito de permitir a indexação mais completa possível de todo e qualquer tipo de bem patrimonial. Estes bens podem ser de natureza material (arquitetônicos, arqueológicos, móveis, integrados, bibliográficos, arquivísticos, etc.) ou imaterial (receitas, festas, depoimentos, etc.) (Figura 1, na próxima página).

Após a identificação da fazenda, cadastrada como instituição de memória para organização de seu acervo, a ficha de indexação dos bens foi dividida em onze grupos de atributos, alguns deles aplicados a todas as espécies de bens patrimoniais e outros mais específicos:

- informaçóes gerais: caracterização da natureza e tipo do bem, incluindo título e localização;

- autoria: cadastro do profissional responsável;

- produção: local, ano e edição;

- descrição: campos descritivos diferenciados de acordo com as especificidades de cada espécie de bem patrimonial, para que sejam descritas suas principais características físicas;

- material audiovisual: local para inserção de imagens, vídeos, áudios, etc. que auxiliem na percepção do bem como um todo, em suas dimensóes material e imaterial;

- diagnóstico e intervenção: estado de conservação e preservação do bem, incluindo registro de possíveis intervençóes realizadas;

- condiçôes de disponibilidade, uso e proteção: utilização atual e possibilidade de consulta do bem, e legislaçóes incidentes sobre ele;

- histórico de procedência: dados de proprietários, formas de aquisição e histórico;

- assuntos e descritores: palavras-chaves;

- fonte de informação: referências consultadas; e

- $\quad$ responsável pela pesquisa.

Como forma de identificar os tipos de bens patrimoniais das fazendas históricas de São Paulo, foi realizada pesquisa de campo em quatro fazendas da regiáo da cidade de São Carlos-SP cujos proprietários se dispuseram a colaborar mais intensamente com os trabalhos de inventário e divulgaçáo de seus acervos. Dessa forma, reuniu-se uma gama variada de itens que possibilitaram testar o PDI para os diversos tipos de bens.

\section{Sistema web}

A segunda frente de pesquisa do projeto apresentado neste artigo aprimora e adapta o sistema web livre "Memória Virtual Rural" (MVR) ao PDI (Figura 2, na próxima página). Os trabalhos neste sistema foram iniciados em 2003 e vêm sendo desenvolvidos em ambiente acadêmico com a disponibilização de estágios aos alunos de graduação do Instituto de Ciências Matemáticas e de Computação - ICMC. Segundo os cientistas da computação brasileiros Elisa Nakagawa e Thiago Bianchi (2013), coordenadores da equipe de programação, este sistema pode abrigar acervos de várias instituições, contendo um grande número de bens e dados.

De acordo com o coordenador do primeiro projeto de pesquisa desta trajetória, o engenheiro elétrico José Carlos Maldo- 


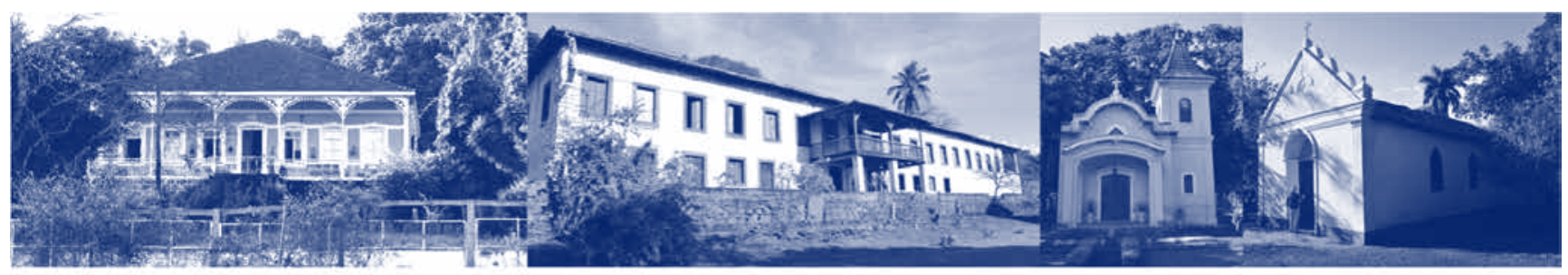

Sedes das fazendas Mandaguahy (Jaú) e Santa Eudóxia (São Carlos); e igrejas das fazendas São Roberto e Santa Eudóxia (São Carlos).

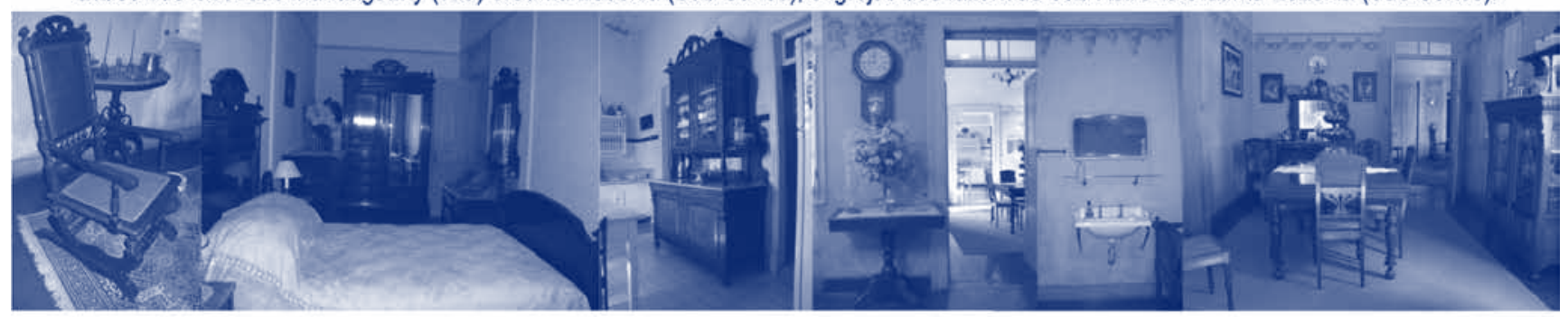

Parte dos bens materiais móveis (mobiliário) e integrados da Fazenda São Roberto (São Carlos).

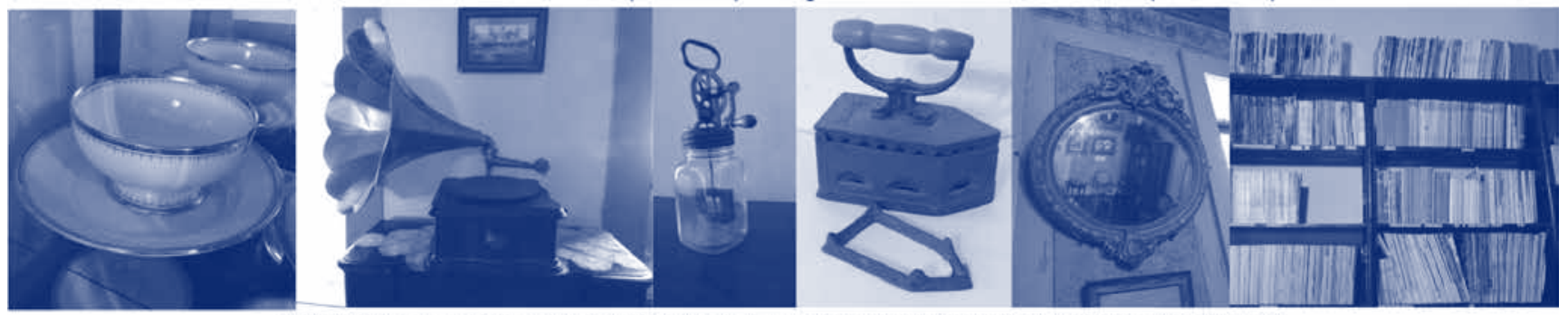

Parte dos bens materiais móveis (utensilios) da Fazenda Santa Maria do Monjolinho (São Carlos).

Figura 1. Exemplos da diversidade de bens patrimoniais encontrados nas fazendas pesquisadas no projeto atual. (Fotos: Grupo de pesquisa Patrimônio cultural: memória, preservação e gestão sustentável.)

nado (2004, p. 1), uma das ideias norteadoras deste sistema era a definição e padronização do acesso e da forma das informaçóes históricas e culturais a serem cadastradas, de modo a garantir sua acessibilidade e qualidade. Neste sentido, realizaram-se os trabalhos da primeira frente de pesquisa deste projeto atual, e atualmente trabalha-se a adequação deste sistema ao PDI desenvolvido. Dessa forma, pretende-se adaptá-lo para uma melhor indexação da vasta gama de bens patrimoniais materiais e imateriais presentes nestas fazendas históricas. Além dos atributos do PDI, o sistema ainda conta com um espaço para relacionar o bem que está sendo cadastrado com os demais bens da base de dados. Desse modo, possibilita que o usuário desenvolva um olhar mais amplo sobre o bem pesquisado, mencionando relaçóes espaciais e históricas entre eles.

O sistema também responde a questôes de segurança ao permitir acesso de catalogador a pessoas convidadas por um administrador da instituição de memória e ao possibilitar a inserção de um bem e sua não liberação para acesso externo. Além disso, a própria instituição pode transformar esta base de dados em um sistema privativo, de modo a ocultar dados de sua localização, reduzindo sua exposiçáo, caso seja de seu interesse. Esta é uma questão importante para o patrimônio rural, pois se percebeu ao longo do projeto que alguns dos proprietários tiveram seu interesse em participar do projeto abafado pelo medo de expor sua localização, pois as áreas rurais estáo mais vulneráveis a roubos.

Apesar da criaçáo desta opçáo de anonimato pela questão de segurança, o sistema é pensado originalmente para a disponibilização dos acervos de modo a atuar como meio para a educação patrimonial e divulgação dos bens referentes às fazendas históricas. Isso porque ainda existe pouco material divulgado sobre este tema tão importante para a formação econômica nacional e para a cultura do Estado de Sáo Paulo. Nas palavras de Maldonado (2004), o sistema web Memória Virtual possui o intuito de que "outras entidades similares (prefeituras, fazendas, associaçóes, etc.) possam também fazer uso desse sistema, beneficiando assim a comunidade em geral, pela disponibilização de seus acervos”.

\section{Considerações Finais}

"A preservação de documentos tem por objetivo assegurar a integridade, autenticidade e acessibilidade a longo prazo dos suportes documentais e da informação contida neles. [...]" (Flores \& Hedlund, 2014, p. 7). O registro do patrimônio em ambiente virtual possibilita uma convergência ao reuni-los em um único banco de dados, permitindo aos proprietários a organização e gestão de seus acervos. E, ao mesmo tempo, também amplia a apropriação deste patrimônio pela comunidade, ao possibilitar seu acesso de qualquer lugar do mundo. Segundo o historiador brasileiro Nicolau Sevcenko (1993), esta digitalizaçáo dos dados converte o concreto em uma forma de linguagem que é facilmente disseminada, de modo que, como menciona o também historiador brasileiro Rogério José de 


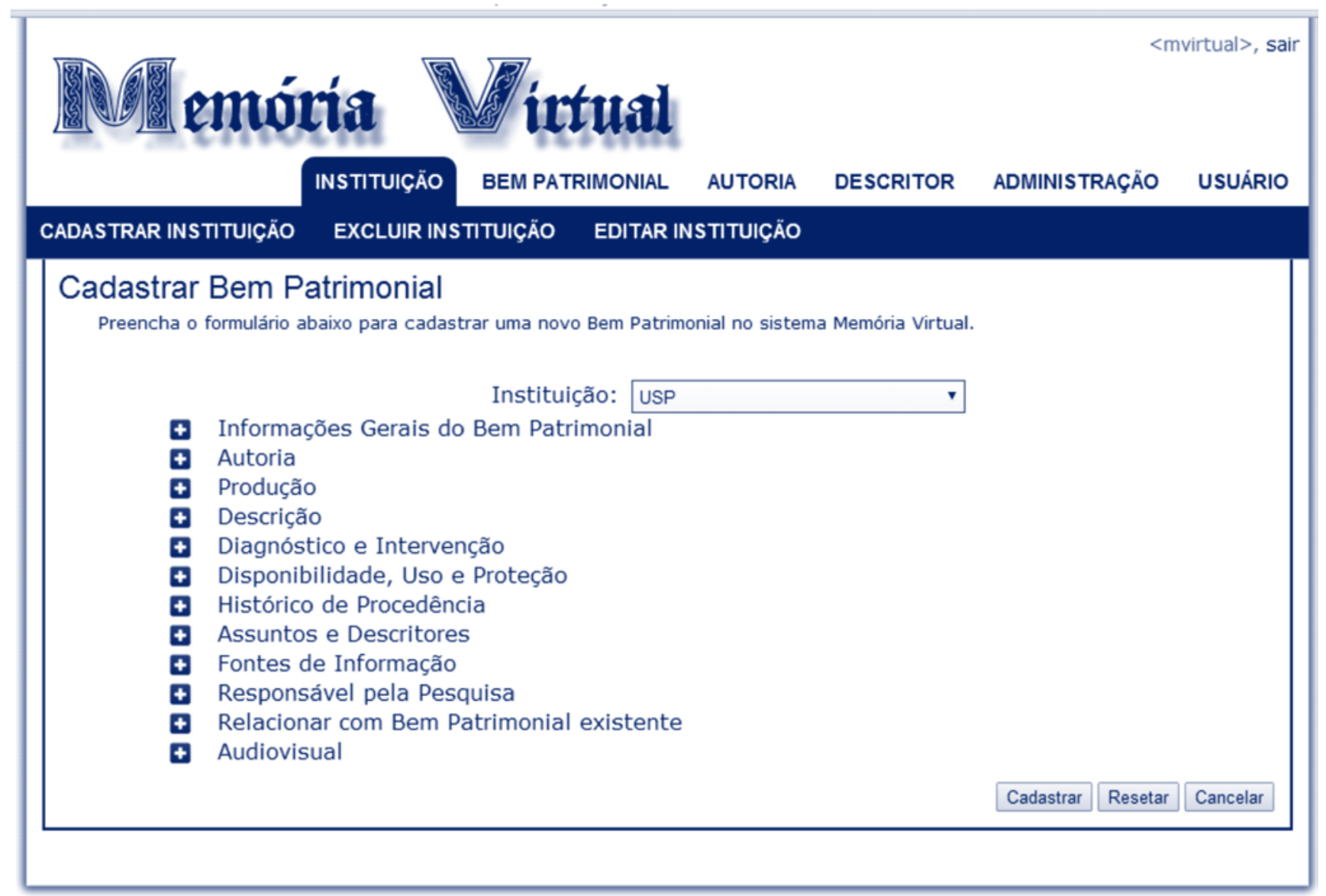

Copyright @ 2009 LABES - Laboratório de Engenharia de Software - ICMC-USP

Figura 2.Interface de cadastro de bens do sistema web Memória Virtual mostrando os grupos de atributos do PDI.

Almeida Santos (2005), passa a ser experienciável pelos usuários. Este processo transforma o virtual em um suporte de memória que, segundo os brasileiros Maria de Fátima Lima, Nelson Pretto e Simone Ferreira (2005), possui um alcance e um potencial disseminador que não é encontrado em nenhum outro meio de comunicação anterior, uma vez que permite que o patrimônio liberte-se dos limites espaço-temporais.

Este registro do acervo das fazendas históricas paulistas em meio digital possibilitaria a preservação de bens patrimoniais em perigo, respondendo especialmente à questáo da preservaçáo daquilo que o historiador inglês Bill Schwarz (1992, p. 70) denomina "memórias e esperanças das pessoas comuns": o patrimônio imaterial dos trabalhadores destas fazendas. Desta maneira, este projeto tem a finalidade de investigar e preservar a memória de um período específico da história nacional cujo valor ainda é ignorado pela sociedade e permitir uma posterior divulgação destas preciosas informaçóes para a população. De modo que desempenha papel essencial para a própria cidadania ao auxiliar a manutençáo da identidade da sociedade brasileira, e também promove a valorização deste patrimônio em âmbito mundial, permitindo sua análise por cidadãos ao redor do mundo.
Ao aplicar-se o PDI aos diversos bens observados nas fazendas, foi possível perceber que esta é uma maneira eficaz para o registro dos bens patrimoniais, abarcando as diversas características descritivas necessárias para o seu pleno entendimento. Pretende-se continuar o trabalho de adequar os campos do sistema web Memória Virtual àqueles que estruturam o PDI. Após a conclusão deste processo de adequação, o sistema será apresentado e testado pelos proprietários das fazendas que demonstrarem interesse ${ }^{2}$.

\section{Agradecimentos}

Nosso agradecimento ao apoio financeiro da Fundação de Amparo à Pesquisa do Estado de São Paulo - FAPESP e do Conselho de Defesa do Patrimônio Histórico, Arqueológico, Artístico e Turístico do Estado de São Paulo - CONDEPHAAT.

\section{Referências}

Costa, L. S. F. (2012). Critérios e metodologias para a realização de inventário do patrimônio cultural paulista. Disponível em: <http:// www.bv.fapesp.br/pt/auxilios/45936/criterios-e-metodologias-para-a-realizacao-de-inventario-do-patrimonio-cultural-paulista/>.

Flores,D.\&Hedlund, D. C. (2014).A preservação do patrimônio documental através da produção de instrumentos de pesquisa arquivísticos e da produçáo de instrumentos de pesquisa arquivísticos e da implementação de repositórios arquivísticos 
digitais. Sér. Patrim. Cult. e Exten. Univ., n. 3. Disponível em: <http://www.iphan.gov.br/baixaFcdAnexo.do?id=4324>.

Lima, M. F. M., Pretto, N. L. \& Ferreira, S. L. (2005). Mídias digitais e educação: tudo ao mesmo tempo agora o tempo todo... In: A. Barbosa Filho, C. Castro\& T. Tome (Orgs.). Mídias digitais: convergência tecnológica e inclusão social. São Paulo: Paulinas, p. 225-255.

Maldonado, J. C. (2004). Memória Virtual de São Carlos. [online] Disponível em: <http://www.bv.fapesp.br/pt/auxilios/5716/ memoria-virtual-de-sao-carlos/>.

Nakagawa, E. \& Bianchi, T. (2013). Sistema Memória Virtual. [Palestra] In: WORKSHOP DISPONIBILIZAÇÃO DE ACERVOS HISTÓRICOS, 1., São Carlos-SP.

Pratschke, A., Bortolucci, M. Â. P. C. \& Costa, L. S. F. (2006). Pinhal digital: uma experiência de transdisciplinaridade. In: N. P. Kuri \& A. N. R. Silva (Orgs.). O ensino no Campus USP São Carlos: inovações e inovadores. v. 1. São Carlos-SP: CETEPE-USP, p. 67-86.

Santos, R. J. A. (2005). Teoria da Informação. [online] Disponível em: <http://a-informacao.blogspot.com.br/2005/07/teoriada-informao.html>.
Schwarz, B. (1992). Patrimônio histórico e cidadania: a experiência inglesa. In: $\mathrm{O}$ direito à memória: patrimônio histórico e cidadania. São Paulo: Departamento do Patrimônio Histórico, p. 67-79.

Sevcenko, N. (1993). ... talvez a última grande batalha e ao mesmo tempo a última grande fronteira seja afinal a cultura. Projeto História, São Paulo, v. 10, p. 100-102.

Tognon, M. (2008). Patrimônio cultural rural paulista: espação privilegiado para a pesquisa, ensino e turismo. [online] Disponível em: <http://www.bv.fapesp.br/pt/auxilios/6214/ patrimonio-cultural-rural-paulista-espacao-privilegiado-para -a-pesquisa-ensino-e-turismo/>.

\section{[Endnotes)}

1 O PDI concebido neste projeto utiliza o universo das antigas fazendas paulistas do período cafeeiro como objeto para teste, mas pode ser aplicado para todas as temáticas de patrimônio.

2 Este sistema também poderá ser utilizado por outras instituições de memória interessadas, já que é pensado como um sistema livre e sua utilização pelo maior número possível de instituições, das mais diversas temáticas patrimoniais, é muito bem-vinda. 